\title{
Uso de sistemas de aeronaves remotamente pilotadas (RPAS) na quantificação de incremento anual em volume de aterro sanitário
}

\section{Jéssika Cristina Nascente ${ }^{\mathbf{1}}$ e Gustavo Manzon Nunes ${ }^{2}$}

\author{
${ }^{1}$ Universidade Federal de Mato Grosso. Faculdade de Engenharia Florestal. \\ Programa de Pós-Graduação em Ciências Florestais e Ambientais. Campus Cuiabá. \\ Av. Fernando Corrêa da Costa, 2367. Boa Esperança. Cuiabá-MT, Brasil (CEP \\ 78060-900). E-mail: engflorestal.jessika@gmail.com. \\ ${ }^{2}$ Universidade Federal de Mato Grosso. Faculdade de Engenharia Florestal. Campus \\ Cuiabá. Av. Fernando Corrêa da Costa, 2367. Boa Esperança. Cuiabá-MT, Brasil \\ (CEP 78060-900).
}

Resumo. 0 presente estudo teve por finalidade obter a quantificação do incremento em volume de resíduos sólidos industriais acumulados no período de um ano (entre 2016 e 2017) nas células de deposição do aterro sanitário do Centro de Gerenciamento de Residuais em Cuiabá (CGR Cuiabá). A análise, foi realizada via dados de Sistemas de Aeronaves Remotamente Pilotadas (RPAS) multirotores de modelos DJI Phantom 4 e Phantom 4 Pro, que permitiram a realização de missões de voo em agosto de 2016 e agosto de 2017, compatibilizadas com a coleta de pontos de controle e estudo do Relatório de Impacto ao Meio Ambiente (RIMA). Visando à ortorretificação e à obtenção de acurácia planimétrica $(\mathrm{x}, \mathrm{y})$ e altimétrica $(\mathrm{z})$, o levantamento de campo utilizou GNSS Geodésico para a aquisição de pontos de controle a partir da instalação de alvos que posteriormente foram corrigidos por sistema pós-processado. A partir dos dados dos RPAS, foram gerados produtos que envolveram a modelagem 3D de alta precisão, onde foi possível realizar a quantificação em volume de cada célula do aterro para cada ano e consequentemente o valor de incremento de resíduos após o período de um ano. Através do processamento da nuvem de pontos densa em 3D e a análise do volume de cada célula para ambos os anos, quantificou-se o incremento de deposição de resíduos no período de um ano sendo igual a 2.727,07 t/mês. Simultaneamente ao processamento dos dados, uma análise documental do histórico do aterro permitiu destacar que os maiores volumes depositados nas células do aterro são referentes aos resíduos de classe II e lodo, e que entre todos os setores industriais que recorrem ao aterro sanitário para deposição final dos seus resíduos, o ramo alimentício é o responsável pelo maior volume depositado. Os resultados deste trabalho sugeriram que mais recursos financeiros poderiam ser investidos para implementar políticas públicas para promover melhores práticas de gestão ambiental proporcionalmente ao surgimento de novas
Recebido

$13 / 02 / 2020$

Aceito

28/07/2020

Disponível on line 09/08/2020

Publicado

$31 / 08 / 2020$

Acesso aberto

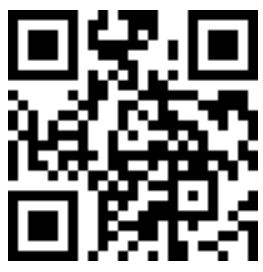

ORCID

D 0000-0001-6111-582X Jéssika Cristina Nascente

(D) 0000-0002-5124-5898 Gustavo Manzon Nunes 
indústrias devido à geração e acúmulo de resíduos, a fim de reduzir e produzir menos impacto ambiental.

Palavras-chave: Células de resíduos; Dados de alta resolução; Nuvem de pontos 3D.

Abstract. Use of remotely-piloted aircraft system to quantification in the annual increase of the landfill's volume. This work aimed at quantifying the increase in volume of solid industrial waste accumulated at the landfill deposit cells of Centro de Gerenciamento de Residuais (CGR) in Cuiabá, Mato Grosso, Brazil, during the period that ranged from 2016 to 2017. The analysis was carried out using data collected by Remote Piloted Aircraft Systems (RPAS) multirotor of models DJI Phantom 4 and Phantom 4 Pro, throughout flight missions performed in August 2016 and August 2017, compatible with the collection of points control and study of the Environmental Impact Report (RIMA). Aiming at orthorectification and obtaining planimetric $(x, y)$ and altimetric (z) accuracy, the field survey used Geodetic GNSS for the acquisition of control points from the installation of targets that were later corrected by a post-processed system. Products that involved high-precision 3D modeling were generated based on RPAS data, therefore, it was possible to quantify the volume of each cell of the landfill for each year and, consequently, the increasing in waste after the period of one year. The increment of waste deposition in the period of one year was quantified through the processing of the dense point cloud in 3D and the analysis of the volume of each cell for both years. Analysis showed an estimated volume of $2.727,07 \mathrm{t} / \mathrm{month}$. Beside data processing and analysis, it was performed a documental analysis of the landfill's history. Results have showed the largest volumes deposited in the landfill cells refer to class II and sludge waste, and that among all industrial sectors that use the landfill as a final disposal of its residues, the food industry is responsible for the largest volume deposited. Results from this work suggested that more financial resources could be invested in order to implement public policies to promote better environmental management practices proportionally to the increase in generation and accumulation of waste in order to reduce environmental impact and produce less environmental impact.

Keywords: Waste cells; High resolution data; 3D point cloud.

\section{Introdução}

Os Sistemas de Aeronaves Remotamente Pilotadas (do inglês, Remotely-Piloted Aircraft System - RPAS) envolvem todo o conjunto de recursos do sistema que possibilita o controle de aeronaves leves do tipo asa fixa ou multirotor, controladas remotamente e acoplada de sensor imageador RGB, infravermelho e/ou termal, denominadas de Aeronave Remotamente Pilotada (do inglês, Remotely-Piloted Aircraft - RPA) (Brasil, 2015; Monteiro, 
2016), no entanto, as aeronaves que não possuem o mecanismo para controle remoto, são chamadas de Veículo Aéreo Não Tripulado (VANT) (Monteiro, 2016).

De modo geral, esses equipamentos vêm substituindo diversas técnicas convencionais, por possibilitar agilidade nos produtos finais, alta resolução espacial, segurança do operador e flexibilidade operacional por apresentar modos de voo livre e missões planejadas, acessibilidade ao local e frequência de imageamento, atuando em: identificação de falhas em plantio (Braga, 2016), construção de Modelo Digital do Terreno (MDT) de áreas de mineração (Lima et al., 2018), monitoramento da vegetação nativa (Lima et al., 2018), operações de vigilância (González-Jorge et al., 2017), quantificação de solo erodido (Siqueira-Junior et al., 2019), aplicações arqueológicas (Vattuone e Monné, 2018), e dentre outras áreas de aplicação.

Considerando o potencial do RPAS e técnicas de processamento para estimar volume, sugere a aplicação desses recursos na gestão de aterros sanitários, logo que Obladen et al. (2009) descreve que a vida útil do aterro sanitário depende do volume de resíduos que ele acomoda sendo necessário o monitoramento constante do fluxo de resíduos nas células de deposição.

Atualmente o planejamento da vida útil e o controle do volume comportado em aterros sanitários são dimensionados por estimativa em função da quantidade de resíduos sólidos a ser disposta ao dia e/ou anualmente, junto a massa específica e a redução volumétrica, adquirida pela taxa de compactação (ABNT, 1992).

Existem outras alternativas de quantificação de estoque de volume em aterro sanitário, como na construção de malha 3D por coleta de pontos com ferramentas topográficas ou com Laser Scanner Terrestre (LST), no entanto, o primeiro é muito oneroso, devido à grande quantidade de pontos necessários a serem instalados (Estima, 2016) e o segundo possui um alto custo do equipamento que o torna inviável (Trindade et al., 2015), ambos contrapondo o baixo custo em obter uma plataforma aérea não tripulada e personalizada (Moutinho et al., 2015).

Em se tratando de aterro sanitário, são locais onde se aplicam técnicas de disposição de resíduos sólidos urbanos no solo com princípios de engenharia ao confinar à menor área possível e reduzi-los ao menor volume permissível, sem causar danos à saúde pública e obter a minimização dos impactos ambientais (ABNT, 1992).

A norma ABT NBR 10.004:2004 (Brasil, 2004) classifica os resíduos sólidos urbanos em industrial, doméstico, hospitalar, comercial, agrícola, de serviços ou de varrição conforme atividade de origem residual, podendo ainda serem agrupados quanto à periculosidade. Desta forma, os aterros sanitários seguem diretrizes e normas para construção e instalação de infraestrutura adequada para a deposição final dos resíduos sólidos que comportam.

Diante do exposto, o presente trabalho objetivou obter o incremento em volume, entre os anos de 2016 e 2017, dos resíduos depositados nas células do aterro sanitário industrial de Cuiabá com base na análise da nuvem de pontos 3D gerada a partir da coleta e processamento das imagens por RPAS. Após a mensuração do volume buscou obter o setor industrial responsável pela maior deposição de resíduos neste aterro sanitário.

\section{Materiais e métodos}

\section{Área de estudo}

O estudo foi realizado no aterro sanitário industrial da empresa CGR - Centro de Gerenciamento de Resíduos em Cuiabá, onde ocupa uma área total de 200.209,16 m² e até 2017, atendia 1.400.000 habitantes, 85 hospitais, farmácias, clínicas e laboratórios.

0 aterro sanitário está localizado na Fazenda Nova Esperança (próximo às

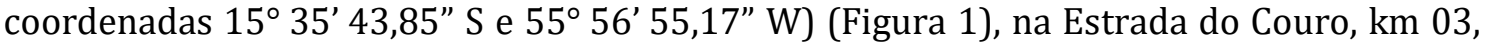


no Distrito de Pascoal Ramos, Bairro Pedra 90, Município de Cuiabá, Mato Grosso, distante $16,5 \mathrm{~km}$ do centro urbano.

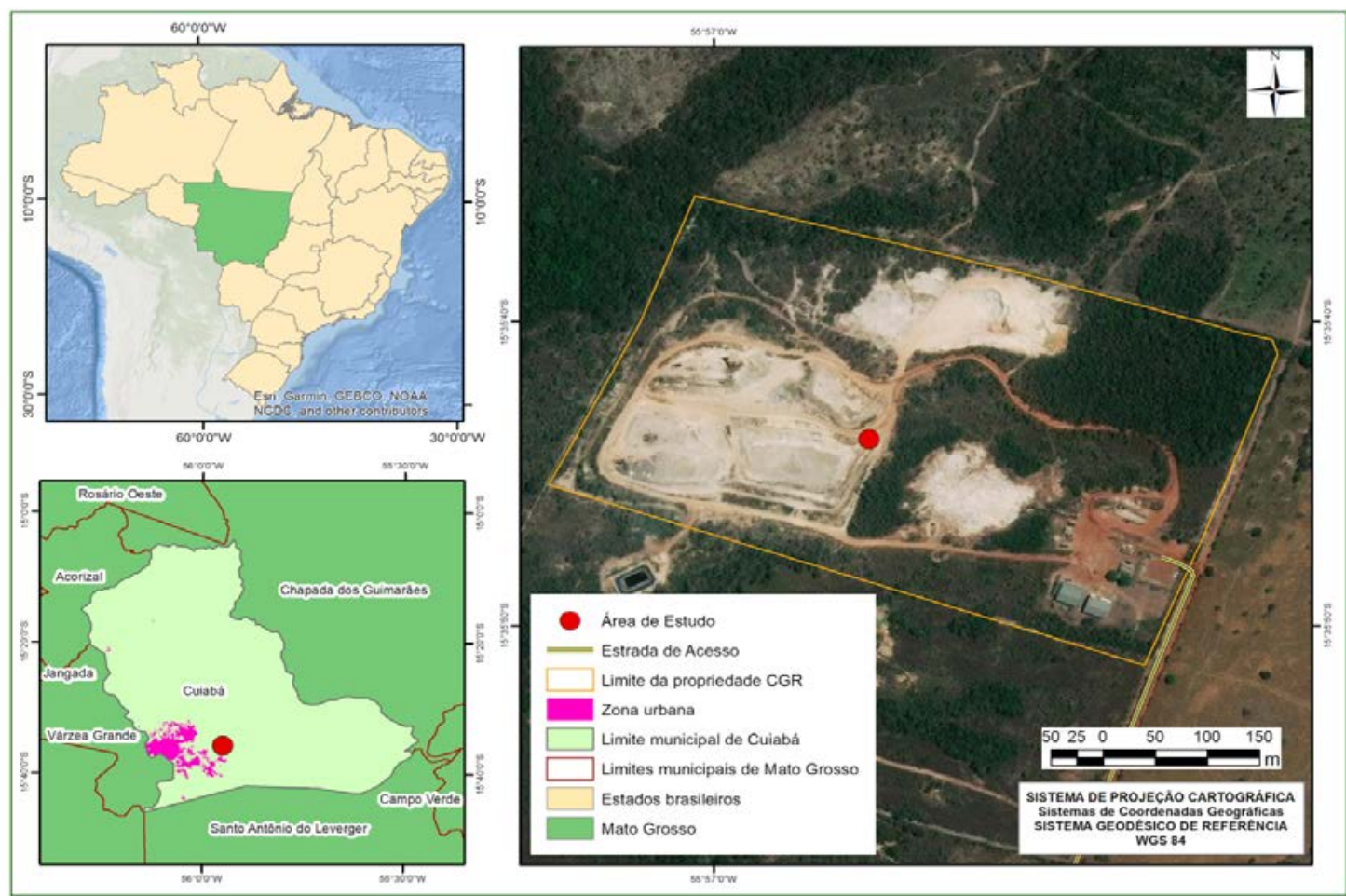

Figura 1. Mapa de localização da área de estudo, Aterro Sanitário Industrial de Cuiabá da empresa CGR.

\section{Aspectos ambientais}

O clima da região é definido como AW, tropical savânico com chuvas no verão e seco no inverno, conforme a classificação de Köppen, (Alvares et al., 2013). A precipitação média anual de $1.400 \mathrm{~mm}$, variando entre 800 e $1.600 \mathrm{~mm}$ com o período chuvoso concentrado de outubro a abril, atingindo cerca de 70\%-80\% da média anual, sendo os maiores níveis de chuvas observados no planalto. A temperatura média anual varia entre $22{ }^{\circ} \mathrm{C}$ e $26{ }^{\circ} \mathrm{C}$, comumente superiores a $38^{\circ} \mathrm{C}$ nos meses de dezembro, janeiro e fevereiro (verão), e mínimas observadas de $18{ }^{\circ} \mathrm{C}$ para os meses de junho, julho e agosto (inverno) (ANA, 2004).

O Município de Cuiabá está inserido no bioma Cerrado, na unidade geomorfológica da Depressão Cuiabana com relevo variando entre 200 e $450 \mathrm{~m}$, caracterizado por modelados de depressão dissecada, pediplanada e planície de inundação do Rio Cuiabá (Ross e Santos, 1982; Vieira-Junior et al., 2011; IBGE, 2019).

\section{Tipos de resíduos do aterro sanitário industrial de Cuiabá}

A CGR trabalha com a logística licenciada pela Secretaria de Estado do Meio Ambiente de Mato Grosso (SEMA/MT) de controle de recebimento de resíduos sólidos industriais da "Classe II-A" e "II-B" para deposição permanente, e "Classe I" para armazenamento temporário. 
Os resíduos de classe I são denominados "perigosos", caracterizados como inflamável, corrosivo, reativo, tóxico e/ ou patogênico, oposto dos resíduos de classe II, os "não perigosos", subdivididos em II-A do tipo "não inertes" (biodegradável, combustível e/ou solúvel em água) e II-B do tipo "inertes" (não solúvel a concentrações dos padrões de potabilidade de água, excetuando-se aspecto, cor, turbidez, dureza e sabor) (ABNT, 2004), os quais são depositados permanentemente em trincheiras, por técnicas de operação de superfície (Portella e Ribeiro, 2014).

\section{Banco de dados}

O levantamento da área de estudo foi realizado em três etapas: coleta de pontos de controle com receptor de Sistema de Navegação Global por Satélite (Global Navigation Satellite System - GNSS) do tipo L1/L2, modelo Topcon Hiper Lite+; captura de imagens aéreas (sobrevoos) com câmeras RGB acopladas em modelos RPAs fabricados pela empresa DJI; e a análise dos dados do Relatório de Impacto Ambiental (RIMA) do aterro sanitário.

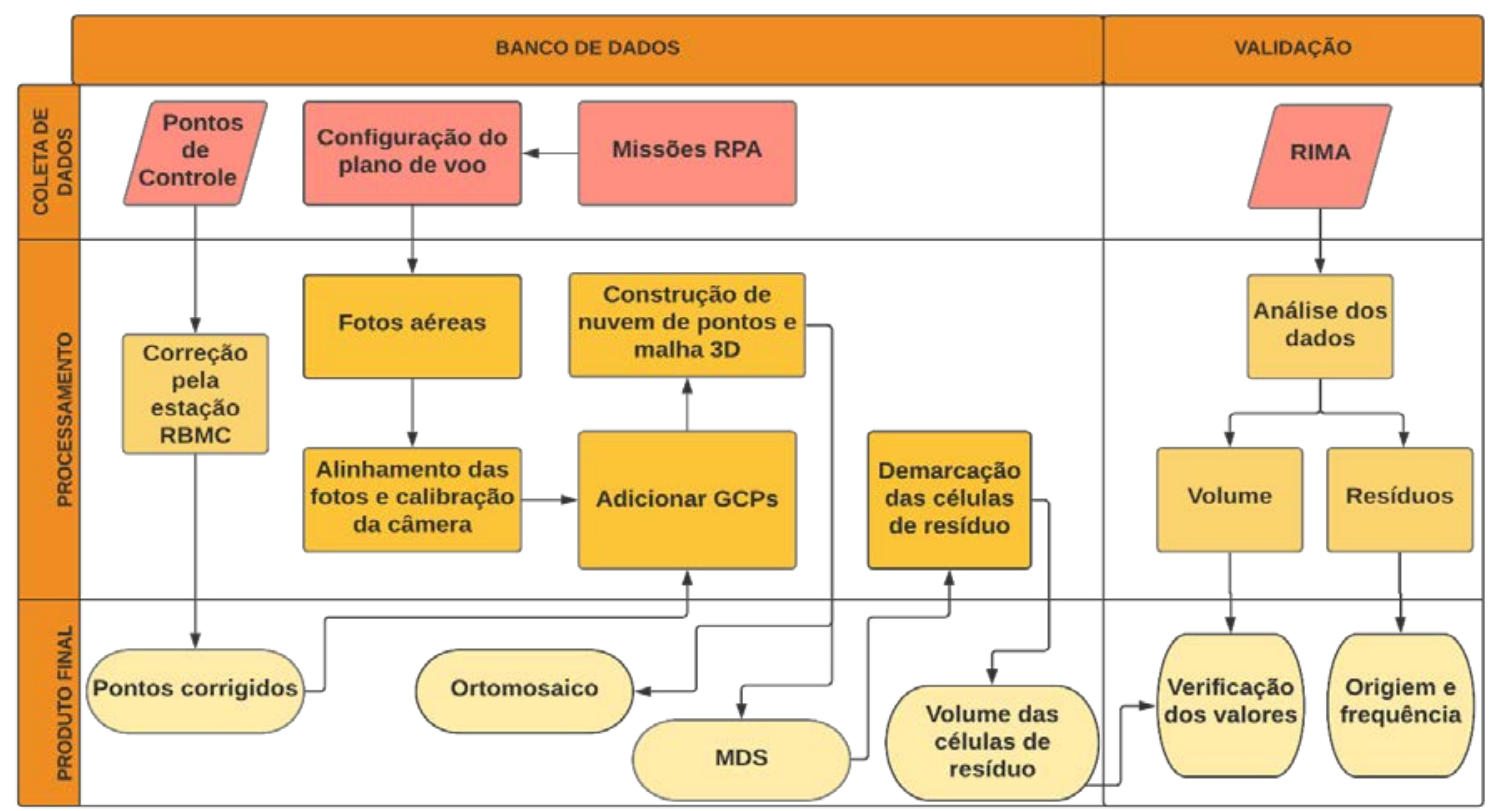

Figura 2. Fluxograma representativo da sequência de processos realizados na metodologia de trabalho.

\section{Coleta de pontos de controle}

Os Pontos de Controle no Solo (GCP) estabelecem uma relação entre o sistema de coordenadas da fotografia aérea e o sistema de coordenadas do terreno, definidos por marco artificial no campo, passível de identificação em fotografias aéreas, proporcionando medições mais precisas (Lopes et al., 2018).

Desta forma, foram demarcados 12 marcos artificiais em cada ano, 2016 e 2017, com cal sobre um molde quadrado com dimensão $40 \mathrm{~cm}$ x $40 \mathrm{~cm}$ (alvo), seguido da coleta do GCP com GNSS no centro do alvo, por método de posicionamento relativo estático-rápido com permanência de 10 min e latência de $1 \mathrm{~s}$, obtendo informações de três constelações de satélites (GPS-EUA, Galileo-Europa e GLONASS-Russo) para solucionar a ambiguidade de um ponto em tempo mínimo (Prina et al., 2015). 


\section{Captura de imagens aéreas}

As campanhas de voo foram realizadas em 18 de junho de 2016 utilizando o RPA DJI Phantom 4 e 18 de junho de 2017, com o RPA DJI Phantom 4 Pro. A substituição do modelo RPA por outro de melhores características técnicas, foi consequência da aquisição do equipamento pelo LabSensoR/FENF/UFMT.

Ambos RPA's possuem um sistema de posicionamento por satélite de banda dupla, GPS e GLONASS (Figueiro et al., 2016) e câmera com sensor CMOS, porém o Phantom 4 Pro ainda se destaca do Phantom 4 por possuir melhor resolução de câmera (20 MP e 12 MP, respectivamente), sensores de detecção de obstáculos, e maior autonomia de bateria ao atingir 30 min, excedendo em 2 min o Phantom 4.

Em vista às particularidades dos equipamentos, foram necessários distintos aplicativos para realizar os planejamentos de voo nos RPA's. Em 2016, foi utilizado o aplicativo DJI Ground Station Pro (GS Pro) compatível com o Phantom 4, e em 2017, utilizado o aplicativo Maps Made Easy recomendado para o Phantom 4 Pro, ambos para sistema operacional iOS, instalados em uma estação de controle Apple Mini Pad 4.

Os planos de voo, constituído de duas missões para recobrimento total da área de estudo, foram ajustados por seleção de polígonos e definida as características de voo em cada ano, demonstradas na tabela abaixo, a fim de buscar maior precisão.

Tabela 1. Características do plano de voo.

\begin{tabular}{|l|c|c|}
\hline Características de voo & $\mathbf{2 0 1 6}$ & $\mathbf{2 0 1 7}$ \\
\hline Quantidade de voos para recobrimento da área (un) & 1 & 2 \\
\hline Altura de voo (m) & 80 & 65 \\
\hline Sobreposição longitudinal (\%) & 75 & 85 \\
\hline Sobreposição lateral (\%) & 80 & 85 \\
\hline
\end{tabular}

\section{Aquisição RIMA}

A Constituição Federal Brasileira de 1988, no art. 225 (Brasil, 1988), trata dos direitos comuns das gerações atuais e futuras referente à garantia da sadia qualidade de vida e o dever do Poder Público em exigir de empresas potencialmente poluidoras, antes da instalação, um estudo prévio de impacto ambiental, a que se dá publicidade efetivando os direitos humanos desta constituição. Portanto, a análise do RIMA do aterro sanitário foi consultado conforme disponibilidade ao acesso público no órgão de responsabilidade ambiental (SEMA/MT).

\section{Processamento dos dados}

Os pontos coletados foram submetidos ao processo de ajustamento no software Topcon Tools pelo método da Rede Brasileira de Monitoramento Contínuo dos Sistemas (RBMC), disponível no Instituto Brasileiro de Geografia e Estatística (IBGE, 2008), para referenciar as coordenadas com o Sistema Geodésico Brasileiro (SGB) por triangulação com o auxílio de duas estações de referência coletas do IBGE.

\section{Aerofotogrametria}

As imagens coletadas pelo RPA foram processadas no software Pix4D Mapper Pro de origem suíça, utilizado com frequência no mercado de agricultura de precisão, meio ambiente e demais áreas (Estima, 2016). O software trabalha com o processamento dividido em três etapas que permitem criar ortomosaico de alta resolução, nuvens de 
pontos em 3D, Modelos Digitais de Elevação (MDE), calcular volumes, além de criar produtos como índices de vegetação.

A primeira etapa do processamento correspondeu a inserção das imagens e as coordenadas dos GCPs corrigidas no software. Ao carregar os dados, o software inicia o processo de alinhamento das imagens pelo algoritmo de visão computacional SIFT (Scale Invariant Feature Transform - Invariante de Escala Recurso de Transformação) que aborda a identificação dos pontos de amarração no conjunto de imagens, suficiente para estabelecer as relações espaciais entre os locais da imagem original em um sistema de coordenadas 3-D arbitrário (Micheletti et al., 2015).

De maneira simultânea, as coordenadas do GPS embarcado no RPA presente nas imagens, foram substituídas pelas coordenadas dos GCPs por método de aerotriangulação, abrangendo essa referência para toda a área e obtendo um mosaico ortorretificado (Figura 2).

A necessidade de uma alta sobreposição para cobrir a geometria completa do objeto ou cena de interesse, dá origem ao algoritmo: Estrutura Derivada de um Sensor em Movimento (do inglês Structure Derived from a Moving Sensor - SfM) (Micheletti et al., 2015), utilizado na segunda etapa de processamento para adquirir dados de nuvem de pontos densa em 3D e altamente detalhados (Micheletti et al., 2015).

Em seguida, a terceira etapa correspondeu a obtenção de ortomosaico e MDE. A obtenção do MDE na área de estudo selecionada expressa diretamente o Modelo Digital do Terreno (MDT) que possui as informações de altimetria a nível do solo, não necessitando de filtragem da nuvem de pontos, logo que o solo estava em condições descobertas nas células de deposição.

Diante do MDT da área de estudo, foram demarcados vértices nas bases das células de deposição de resíduos para quantificação do volume, considerando que todo o limite base da célula de resíduo estava visível, utilizando-se o software Pix4D Mapper adotandose a "superfície de base" com método de "Triangulação" que conecta todos os vértices e triangula o volume acima e abaixo da superfície na base demarcada.

\section{Análise do RIMA}

O RIMA apresentou características para a deposição dos resíduos e planilhas de controle de recebimento dos RSU no aterro. As características para a deposição dos resíduos discriminaram uma taxa de $1.000 \mathrm{~kg} / \mathrm{m}^{3}$ de compactação e $11 \%$ de solo sobre o volume de resíduo total para recobrimento da frente de trabalho. Assim, após a obtenção do volume pelo software Pix 4 D das células de deposição, foi retirado $11 \%$ do volume, referente ao solo, e posteriormente aplicado o inverso da taxa de compactação, para obtenção do volume de resíduo depositado no ano avaliado.

Posteriormente, foi contabilizado a diferença de volume de RSU entre os anos de 2016 e 2017 para obtenção do volume de incremento anual, seguido de uma distribuição de aritmética simples para obtenção do volume de incremento ao mês.

Em outra etapa de análise do RIMA, foram verificadas as planilhas de controle de recebimento dos RSU do ano de 2013 e 2015, últimos anos atualizados no relatório, obtendo diagnóstico do tipo e origem do resíduo que mais recorre ao aterro sanitário para disposição final.

A consulta ao RIMA de monitoramento possibilitou analisar o período entre $2016 \mathrm{e}$ 2017 quanto ao volume de resíduo previsto para ser depositado no aterro, até sua capacidade máxima. 


\section{Resultados e discussões}

As três etapas de processamento no software Pix $4 D$ permitiu a construção do ortmosaico ortorretificado devido coleta de GCPs, e identificação de quatro células em 2016 e três células em 2017 de deposição no aterro sanitário (Figura 3).

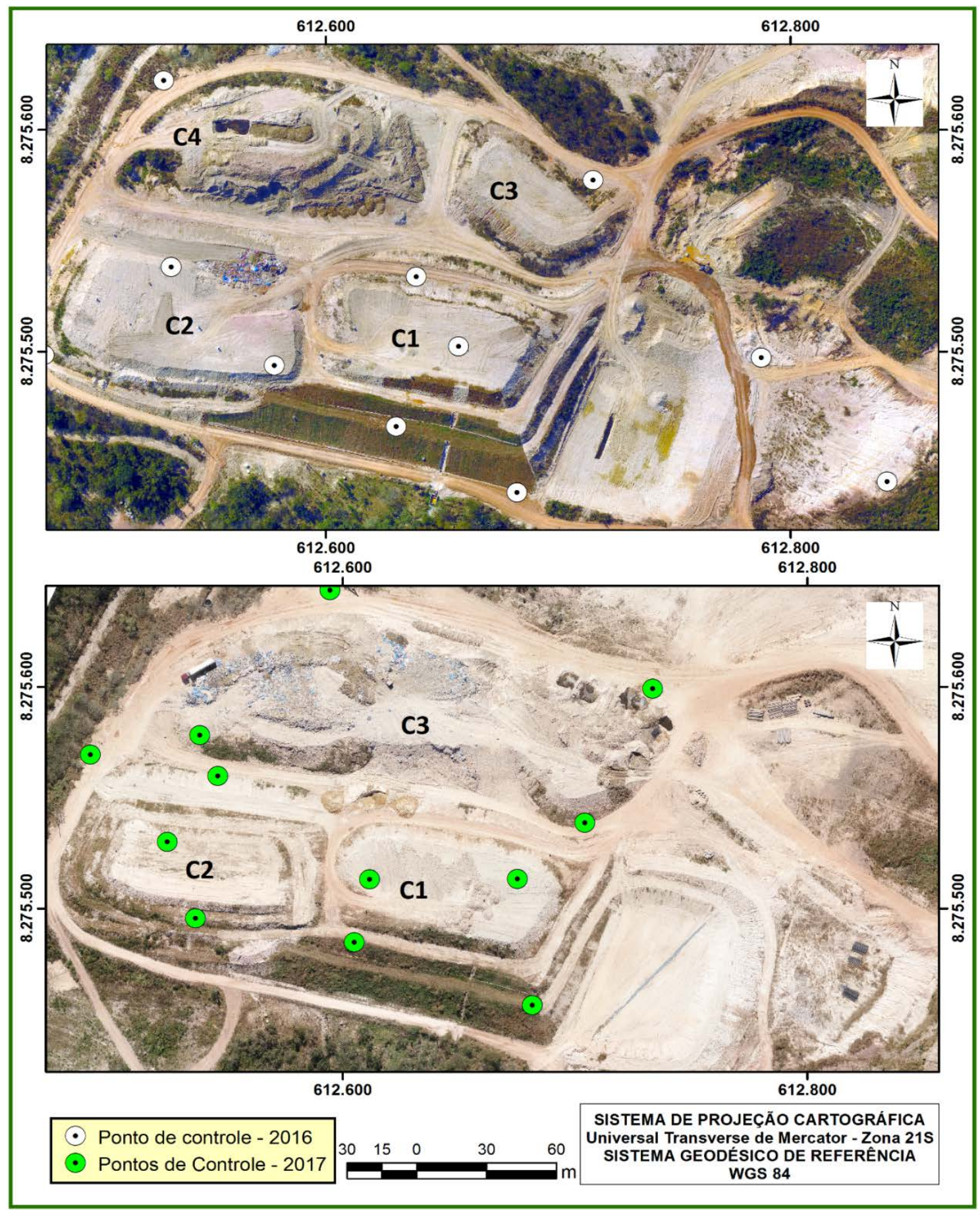

Figura 3. Ortomosaicos com alocação dos alvos para coleta dos pontos de controle e identificação das células com volume quantificados com a letra C. 0 ortomosaico superior refere ao ano de 2016 (4 células) e inferior refere-se ao ano de 2017 (3 células). 
Com o uso dos pontos de controle constatou que a Raiz do Erro Quadrático Médio (RMSE em inglês) apresentado nos relatórios de processamento de ambos os anos de avaliação (2016 e 2017) não ultrapassou 16 cm.

0 processo de ortorretificação para imagens áreas de 2016 gerou um ortomosaico com uma resolução de pixel (GSD) de $4 \mathrm{~cm} /$ pixel. Os RPAS possuem boa precisão e processamento em tempo hábil na construção de MDT para condições de solo descoberto (Lima et al., 2018).

As configurações distintas nas características do plano de voo entre um ano e outro foi necessário devido ao uso de distintas câmeras e da variação no estoque de volume das células de deposição de resíduos, sendo que as incertezas na quantificação do volume diminuem conforme menor o GSD (em centímetros) ao se analisar células de maior altura e irregularidade. Assim, em 2017, as novas características de plano de voo forneceram um ortomosaico de maior resolução, com um GSD de aproximadamente $2 \mathrm{~cm} /$ pixel obtendo maior nitidez dos objetos. As missões de voo de 2017 obtiveram 703 fotos e sobreposição longitudinal e lateral 85\% enquanto em 2016 obteve-se 202 fotos e sobreposição longitudinal 75\% e lateral 80\%, gerando uma nuvem de pontos mais densa em 2017 devido a maior quantidade de imagens sobrepostas.

A partir da nuvem densa de pontos 3D, a identificação de quatro células em 2016 e três células em 2017 foi possível demarcar vértices no início da elevação de cada célula (Figura 4 e 5), para construção do polígono no entorno do estoque, resultando no volume $\left(\mathrm{m}^{3}\right)$ total de cada célula pelo software Pix $4 D$ (Tabela 2). Pode-se observar que para a quantificação do volume das células 1 e 2 para ambos os anos, foi necessário a demarcação dos vértices do polígono envolvendo a base total das duas células, pois o material existente na subdivisão entre elas também era composto por resíduos.

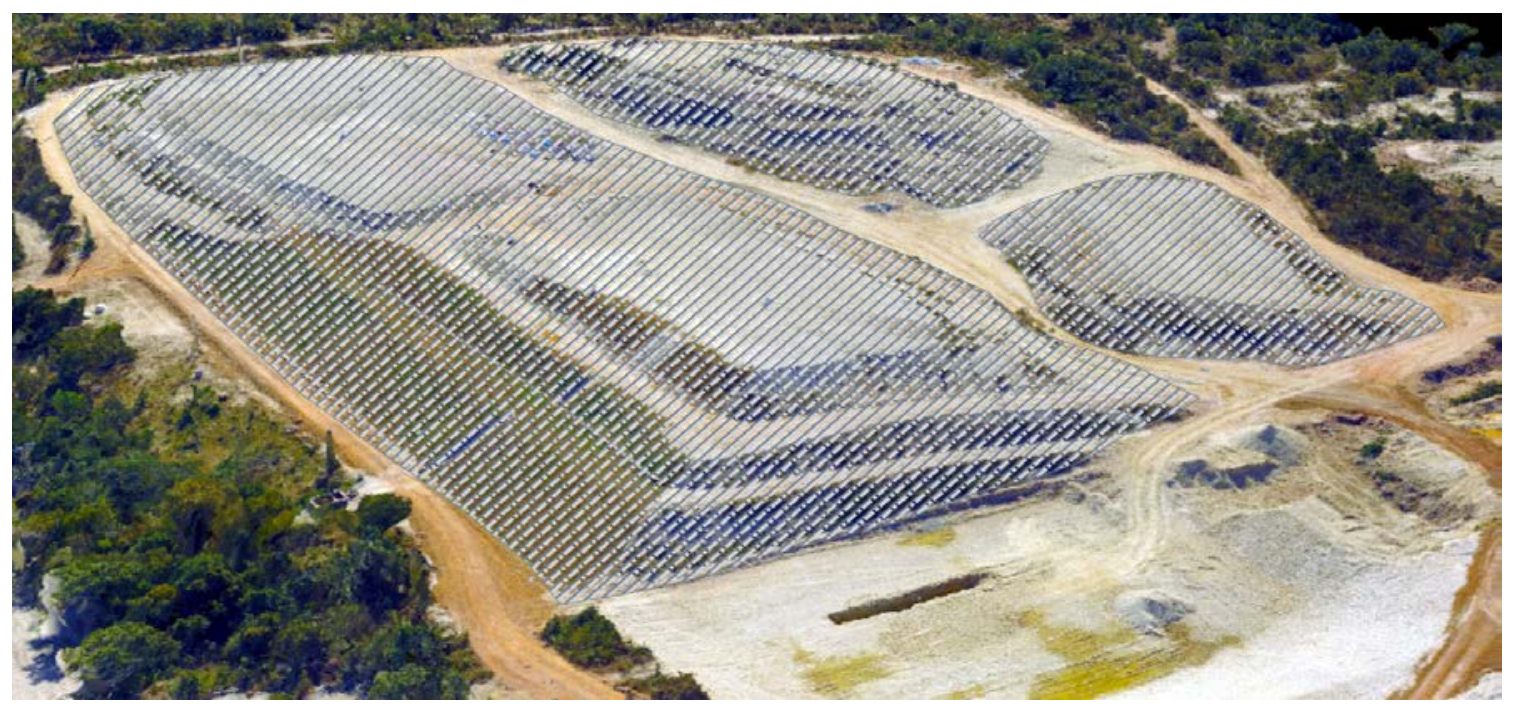

Figura 4. Ortomosaico sob mesma perspectiva ilustrando a demarcação em hachurado das células para a quantificação dos volumes no ano de 2016. 


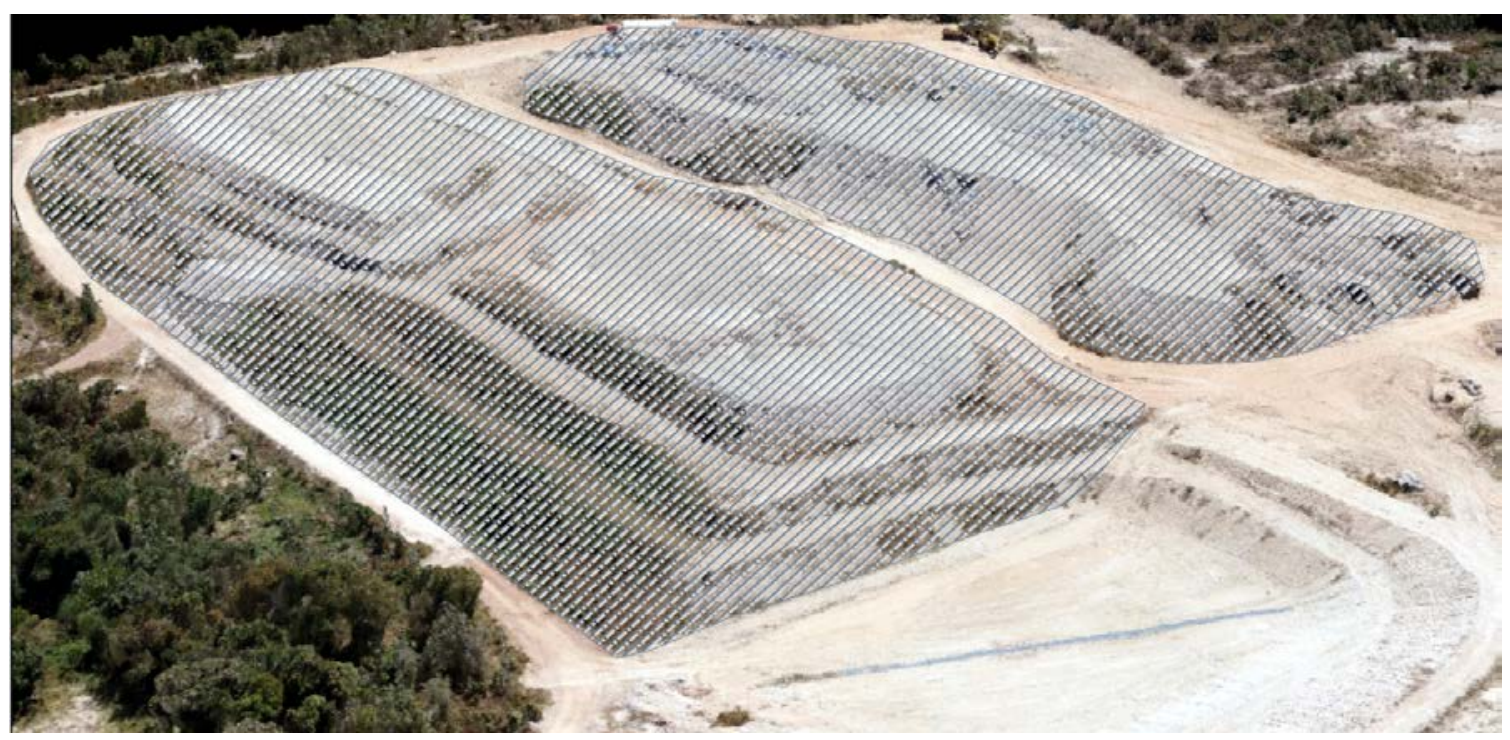

Figura 5. Ortomosaico sob mesma perspectiva ilustrando a demarcação em hachurado das células para a quantificação dos volumes no ano de 2017.

Tabela 2. Volumes mensurados das células de deposição de resíduos para quantificação do incremento em volume entre os anos de 2016 e 2017.

\begin{tabular}{|l|c|c|c|}
\hline & $\mathbf{2 0 1 6}$ & $\mathbf{2 0 1 7}$ & Incremento $\mathbf{( m}^{\mathbf{3}} \mathbf{)}$ \\
\hline Vértices (un.) & 183 & 156 & - \\
\hline Volume $\left(\mathrm{m}^{3}\right)$ & $130.414,86$ & $167.184,40$ & $36.769,54$ \\
\hline Erro $\left(\mathrm{m}^{3}\right)$ & $1.777,35$ & 976,85 & $-800,50$ \\
\hline
\end{tabular}

No cálculo de volume gerado pelo software deve-se considerar: o tamanho do estoque mensurado, a marcação da base (início da elevação do estoque a ser mensurado) e o GSD para melhorar a precisão (Pix4d, 2017). 0 estoque a ser mensurado com geometria mais irregular, deve ser recoberto por uma nuvem de pontos suficientemente densa (Dutescu, 2006). A marcação de cada vértice para criação do polígono na base do estoque deve ser adensada para construir a rede de triangulação que recobre o relevo (Pix4d, 2017).

Portanto, em 2017 as adaptações no plano de voo devido ao aumento do estoque e o revolvimento, resultaram em um menor erro em volume quando observado o estoque em 2016. Ressalta-se que os vértices em 2016 obtiveram maiores quantidades devido às células C3 e C4 se tornarem apenas uma em 2017.

A estimativa do volume de incremento recebido entre o ano de 2016 e 2017 foi de $36.769,54 \mathrm{~m}^{3}$, correspondendo a $2.727,07 \mathrm{t} /$ mês de volume de incremento depositados no aterro sanitário.

O volume de resíduo depositado no aterro estimado pelo software se aproximou da média de resíduos calculados de forma convencional em 2013 (1.422,87 t/mês) e em 2015 (2.336,65 t/mês), considerando o aumento do volume devido ao crescimento populacional da época.

Estima (2016) identificou que o volume do aterro mensurado pela tecnologia RPAS se diferiu apenas $0,28 \%$ dos calculados pela topografia convencional. Sendo assim, uma importante questão aprofundar as técnicas usadas para estimar volume por essa tecnologia. 
Em análise ao RIMA obteve-se que o ranking de maior volume de resíduos por setor industrial depositados no aterro sanitário pertence ao ramo alimentício (16\%), de bebidas (10\%), frigoríficos (10\%) e escritórios em geral (10\%). A discriminação do resíduo depositado permite observar o fluxo de resíduos gerados no perímetro urbano de responsabilidade do respectivo aterro sanitário, influenciar as políticas públicas de educação ambiental (redução, reuso e reciclagem dos resíduos) e apoiar a tomada de decisão das estratégias para o manejo correto dos materiais regulamentadas pela Lei $\mathrm{n}^{\mathbf{0}}$ 12.305/2010 (Brasil, 2010).

Independente do setor industrial os resíduos depositados no aterro sanitário são de $40 \%$ não reciclável da classe II, $40 \%$ de lodo, $9 \%$ de esterco, $5 \%$ vísceras, $4 \%$ chorume e $2 \%$ resíduos da saúde, tendo grande peso ambiental os dois primeiros a julgar ainda pelo volume de descarte.

Os dois resíduos ocupando $80 \%$ do volume depositado no aterro geram preocupação ambiental e por isso exigem medidas socioeconômicas. As práticas artesanais vêm movimentando o mercado em mais de 50 milhões/ano (SEBRAE, 2017) com incentivos governamentais (Portal Brasil, 2015) com intuito de diminuir a deposição final de resíduos não recicláveis da classe II em aterro sanitário. Já o volume do lodo pode diminuir se houver o aproveitamento energético do mesmo dentro das próprias indústrias, logo que ele produz um rendimento de até $19 \%$ para produção de energia $(16,2 \mathrm{Mj} / \mathrm{Kj}$ ) (Pasquini, 2014) ou até um investimento em secador rotativo, completamente viável economicamente (Meneghini, 2015).

\section{Conclusões}

Foi possível a quantificação do volume das células de deposição de resíduos pela nuvem densa de pontos 3D. Ao observar os parâmetros de plano de voo da missão de 2017 e 2016, constatou que quanto mais alta e irregular a superfície do estoque a ser quantificado, menor deve ser a altura de voo e maior devem ser as sobreposições das imagens para gerar o máximo de densidade na nuvem de pontos 3D e assegurar um modelo de estimativa de volume com maior precisão nos eixos "X", "Y" e "Z", por este software.

Obteve-se, ainda, que o setor industrial do ramo alimentício gera maiores resíduos e consequentemente, apresenta maior volume depositado no aterro sanitário. No geral, os resíduos de maior deposição (lodo e resíduos de classe II) podem diminuir seus percentuais mediante políticas públicas de redução, reutilização e reciclagem de resíduos.

Sendo assim, os resultados deste trabalho sugeriram que mais recursos financeiros poderiam ser investidos para implementar políticas públicas para promover melhores práticas de gestão ambiental proporcionalmente ao surgimento de novas indústrias devido à geração e acúmulo de resíduos, a fim de reduzir e produzir menos impacto ambiental.

\section{Conflito de interesses}

Os autores declaram não haver conflitos de interesse.

\section{Referências}

ABNT - Associação Brasileira de Normas Técnicas. ABNT NBR 10.004:2004: Resíduos Sólidos - Classificação. Rio de Janeiro: ABNT, 2004. 
ABNT - Associação Brasileira de Normas Técnicas. ABNT NBR 8.419:1992: Apresentação de projetos de aterros sanitários de resíduos sólidos urbanos Procedimento. Rio de Janeiro: ABNT, 1992.

Alvares, C. A.; Stape, J. L.; Sentelhas, P. C.; Gonçalves, J. L. M.; Sparovek, G. Köppen's climate classification map for Brazil. Meteorologische Zeitschrift, v. 22, n. 6, p. 711-728, 2013. https://doi.org/10.1127/0941-2948/2013/0507

ANA - Agência Nacional de Águas. Implementação de práticas de gerenciamento integrado de bacia hidrográfica para o Pantanal e Bacia do Alto Paraguai. Brasília: ANA/GEF/PNUMA/OEA, 2004. (Relatório final). Disponível em: $<$ http://arquivos.ana.gov.br/projetos/gefpantanal/PAE_Pantanal_PT.pdf>. Acesso em: 07 out. 2019.

Braga, R. O. Monitoramento de plantio de Eucalyptus urophylla ST Blake por aeronaves remotamente pilotadas (RPA). Paragominas: Universidade Federal Rural da Amazônia, 2016. (Monografia de graduação).

Brasil. Lei no 12.305, de 2 de agosto de 2010. Institui a Política Nacional de Resíduos Sólidos; altera a Lei no 9.605, de 12 de fevereiro de 1998; e dá outras providências. Disponível em: <http://www.planalto.gov.br/ccivil_03/_ato20072010/2010/lei/l12305.htm>. Acesso em: 07 out. 2019.

Brasil. Portaria DECEA no 415, de 9 de novembro de 2015. ICA 100/40: Sistemas de aeronaves remotamente pilotadas e o acesso ao espaço aéreo brasileiro. Disponível em: <https://bdex.eb.mil.br/jspui/bitstream/123456789/447/1/ica_100-40_20151119.pdf>. Acesso em: 07 out. 2019.

Brasil. Constituição da República Federativa do Brasil de 1988. Disponível em: <http://www.planalto.gov.br/ccivil_03/constituicao/constituicao.htm>. Acesso em: 07 out. 2019.

Braz, A. M.; Borges, J. P. S.; Bernardes, D. C. S.; Terezan, L. H. Análise da aplicação de VANT na atualização de cadastro florestal com uso de pontos de controle. Anais XVII Simpósio Brasileiro de Sensoriamento Remoto, João Pessoa, 2015.

Dutescu, E. Digital 3D Documentation of Cultural Heritage Sites Based on Terrestrial Laser Scanning. Alemanha: Universität der Bundeswehr München, 2006. (Dissertação de mestrado).

Estima, M. I. D. R. Comparação de modelos tridimensionais produzidos com imagens adquiridas por UAV e avaliação de volumes. Águeda, Portugal: Universidade de Aveiro, Escola Superior de Tecnologia e Gestão de Águeda, 2016. (Dissertação de mestrado).

Ferreira, A. M. R.; Roig, H. L.; Marotta, G. S.; Menezes, P. H. B. J. Utilização de aeronaves remotamente pilotadas para extração de mosaico georreferenciado multiespectral e modelo digital de elevação de altíssima resolução espacial. Anais do XVI Seminário Brasileiro de Sensoriamento Remoto, Foz do Iguaçu, 2013.

Figueiredo, E. O.; D’Oliveira, M. V. N.; Figueiredo, S. M. M. Uso de aeronaves remotamente pilotadas (ARP) no planejamento florestal. Anais do VII Simpósio Brasileiro de Agropecuária Sustentável, Sinop, 2016.

González-Jorge, H., Bueno, M., Martínez-Sánchez, J.; Arias, P. Plano solar não-mantido solar de baixa altitude para prevenção de incêndio florestal: aplicação ao Parque Natural de Serra do Xures (Espanha). International Archive Photogramme Sensoriamento Remoto Information Spacial Science, v. XLII-2/W6, p. 135-139, 2017. https://doi.org/10.5194/isprs-archives-XLII-2-W6-135-2017 
IBGE - Instituto Brasileiro de Geografia e Estatística. Recomendações para levantamentos relativos estáticos - GPS. 2008. Disponível em: <http://www.inde.gov.br/images/inde/ recom_gps_internet.pdf>. Acesso em: 09 ago. 2019.

IBGE - Instituto Brasileiro de Geografia e Estatística. Estado de Mato Grosso - Geologia. 2019. Disponível em: <https://mapas.ibge.gov.br/tematicos.html>. Acesso em: 07 out. 2019.

Lima, R. P.; Coelho, C.; Vinueza, G.; Grassi, J. T.; Castiglione, L. H. G. 0 uso de RPAS Sistemas de Aeronaves Pilotadas Remotamente no mapeamento topográfico para mineração. International Engineering Journal, v. 71, n. 2, p. 281-287, 2018. https://doi.org/10.1590/0370-44672017710120

Lopes, G. A.; Mozer, T. S.; Carli, A. A. Comparative analysis of biogas generation for the solid waste sector using Unmanned Aerial Vehicle with the Brazilian model of greenhouse gas emissions in areas with no operational history. Bulletin of Geodetic Sciences, v. 24, n. 1, p. 98-124, 2018. https://doi.org/10.1590/s1982-21702018000100008

Meneghini, C.; Proinelli, R. F. Análise de viabilidade da queima de lodo frigorífico em uma caldeira à lenha. Unoesc \& Ciência - ACET, edição especial, p. 7-14, 2015.

Micheletti, N.; Chandler, J. H.; Lane, S. N. Structure from motion (SFM) photogrammetry. In: Clarke, L. E.; Nield, J. M. (Eds.). Geomorphological techniques. London: British Society for Geomorphology, 2015.

Monteiro, L. R. Otimização de um sistema de transportes de medicamentos via UAV (drone) entre hospitais do Rio de Janeiro. Rio de Janeiro: Escola Politécnica da Universidade Federal do Rio de Janeiro, 2016. (Projeto de Graduação em Engenharia Civil).

Moutinho, O.; Rodrigues, A.; Gonçalvez, J. A.; Sousa, J. J.; Bento, R. Estudo comparativo de software fotogramétrico em diferentes ambientes com RPAS: comercial vs. open source. Anais da VIII Conferencia Nacional de Cartografia e Geodesia, Portugal, 2015.

Obladen, N. L.; Obladen, N. T. R.; Barros, K. R. Guia para elaboração de projetos de aterros sanitários para resíduos sólidos urbanos: Pólo Paraná. Curitiba: CREA, 2009. (Série de publicações temáticas do CREA-PR).

Pasquini, N. C. Uso potencial como fonte de energia de lodo proveniente de esgoto doméstico e industrial. Revista Ciências Exatas e Naturais, v. 16, n. 1, p. 35-57, 2014.

Pix4D. Pix4D Support. 2017. Disponível em: <https://support.pix4d.com/hc/enus/articles/208652926\#label22\&gsc.tab=0 >. Acesso em: 11 ago. 2019.

Portal Brasil. Governo federal apoia desenvolvimento do artesanato. Ministério da Cultura. 2015. Disponível em: <http://www.brasil.gov.br/cultura/2015/03/governo-federalapoia-desenvolvimento-do-artesanato-brasileiro >. Acesso em: 11 ago. 2019.

Portella, M. O.; Ribeiro, J. C. J. Aterros sanitários: aspectos gerais e destino final dos resíduos. Revista Direito Ambiental e Sociedade, v. 4, n. 1, p. 115-134, 2014.

Prina, B. Z.; Trenti, R. GPS x GNSS: constelação GLONASS maximizando a precisão e acurácia dos dados. Revista Eletrônica em Gestão, Educação e Tecnologia Ambiental, v. 19, n. 2, p. 344-352, 2015.

Roig, H. L.; Ferreira, A. M. R.; Menezes, P. H. B. J.; Marotta, G. S. Uso de câmera de baixo custo acopladas a veículos aéreos leves no estudo do aporte de sedimentos no Lago Paranoá. Anais do XVI Seminário Brasileiro de Sensoriamento Remoto, Foz do Iguaçu, 2013. 
Ross, J. L. S.; Santos, M. L. Geomorfologia. In: Folha SD.21/Cuiabá. BRASIL/Ministério das Minas e Energia. Secretaria Geral, Projeto RADAMBRASIL (Levantamento dos Recursos Naturais, 26). Rio de Janeiro, 1982. p. 189-251.

Santos, L. F. B. Avaliação de modelo digital de terreno gerado através de VANT em planícies pantaneiras. Cuiabá: Universidade Federal de Mato Grosso, 2016. (Monografia de graduação).

SEBRAE - Serviço Brasileiro de Apoio às Micro e Pequenas Empresas. Mercado de artesanato em crescimento. 2017. Disponível em: <https://www.sebrae.com.br/sites/PortalSebrae/artigos/mercado-de-artesanato-emcrescimento,fdfa6915c49a4410VgnVCM1000003b74010aRCRD\#>. Acesso em: 11 ago. 2019.

Siqueira Junior, P.; Silva, M. L. N.; Cândido, B. M.; Avalos, F. A. P.; Batista, P. V. G.; Curi, N.; Lima, W.; Quinton, J. N. Assessing water erosion processes in degraded area using unmanned aerial vehicle imagery. Revista Brasileira de Ciência do Solo, v. 43, e0190051, 2019. https://doi.org/10.1590/18069657rbcs20190051

Souza, P. A.; Mota, L. L.; Zamadei, T.; Martim, C. C.; Almeida, F. T.; Paulino, J. Classificação climática e balanço hídrico climatológico no estado de Mato Grosso. Nativa, v. 1, n. 1, p. 34-43, 2013.

Trindade, C. A.; Cancela, J. F. M.; Silva, M. V. T.; Paoli, B. L. Estimativa de volume de área minerada utilizando técnica de Structure from Motion. Anais do XVII Simpósio Brasileiro de Sensoriamento Remoto, João Pessoa, 2015.

Vattuone, M. M. S.; Monné, J. L. P. Aplicación de los drones em diversos contextos arqueológicos y en casos de reconstrucción geoarqueológica. Comechingonia - Revista Arqueología, v. 22, n. 1, p. 271-293, 2018.

Vettorazzo, F. C. Resíduos sólidos urbanos: riscos relacionados à incineração. Maringá: Pontifícia Universidade Católica do Paraná, 2012. (Dissertação de graduação em Direito).

Vieira Junior, H. T.; Moraes, J. M.; Schobbenhaus, C. Geoparque Chapada dos GuimarãesMT: proposta. Goiânia: CPRM, 2011. Disponível em: <http://rigeo.cprm.gov.br/xmlui/ bitstream/handle/doc/17167/guimaraes.pdf>. Acesso em: 07 out. 2019. 